\title{
Purification and HPLC Analysis of Cell Wall Muropeptides from Caulobacter crescentus
}

Gabriele Stankeviciute ${ }^{1}$ and Eric A. Klein ${ }^{1,2, *}$

${ }^{1}$ Center for Computational and Integrative Biology, Rutgers University-Camden, Camden, NJ, 08102, USA; ${ }^{2}$ Biology Department, Rutgers University-Camden, Camden, NJ, 08102, USA

*For correspondence: eric.a.klein@rutgers.edu

[Abstract] The peptidoglycan sacculus, or cell wall, is what defines bacterial cell shape. Cell wall composition can be best characterized at the molecular level by digesting the peptidoglycan murein polymer into its muropeptide subunits and quantifying the abundance of muropeptides using highpressure liquid chromatography. Certain features of the cell wall including muropeptide composition, glycan strand length, degree of crosslinking, type of crosslinking and other peptidoglycan modifications can be quantified using this approach. Well-established protocols provide us with highly-resolved and quantitatively reproducible chromatographic data, which can be used to investigate bacterial cell wall composition under a variety of environmental or genetic perturbations. The method described here enables the purification of muropeptide samples, their quantification by HPLC, and fraction collection for peak identification by mass spectrometry. Although the methods for peptidoglycan purification and HPLC analysis have been previously published, our method includes important details on how to reequilibrate the column between runs to allow for automated analysis of multiple samples.

Keywords: LD-crosslinks, Transpeptidation, Muropeptides, High-pressure liquid chromatography, Gram-negative bacteria, Bacterial cell wall, Consecutive LC samples

[Background] Most bacteria are encased in a rigid mesh-like protective layer called peptidoglycan (PG) that is synthesized during cell growth and division. PG is a continuous polymer network made of glycan strands consisting of alternating $\mathrm{N}$-acetylglucosamine (GlcNAc) and $\mathrm{N}$-acetylmuramic acid (MurNAc) sugars linked by $\beta(1 \rightarrow 4)$ bonds. Peptide stems attached to the MurNAc sugars are the site of PG crosslinking. While the glycan sugars are largely-conserved in Gram-negative and Gram-positive species, the sugar backbone can be modified via $\mathrm{N}$-deacetylation, $\mathrm{N}$-glycolylation and O-acetylation. These modifications provide resistance to host defense mechanisms against infections, namely lysozyme resistance (Vollmer, 2008). By contrast, the compositions of the peptide strands vary significantly. During pentapeptide synthesis the bacterial family of Mur-ligases can introduce a variety of amino acids at each position of the pentapeptide stem. For example, at the third position of the pentapeptide most Gram-negative species incorporate meso-diaminopimelic acid (mDAP), while most Gram-positives insert L-lysine, although other variations have also been reported (Vollmer, 2008). Additionally, the peptide stem can be modified after synthesis. For instance, Corynebacteriales are reported to modify the third residue meso-Diaminopimelic acid via amidation once peptide synthesis has occurred (Levefaudes et al., 2015). Another aspect of peptidoglycan variation is the type of crosslinking used to connect multiple glycan strands (Schleifer and Kandler, 1972). Transpeptidation by DD- 
transpeptidases creates a 3-4 cross-linkage between third-position mDAP and fourth-position D-alanine. LD-transpeptidases, by contrast, form 3-3 crosslinks between two mDAP residues.

The sacculus, which provides the cell its architectural framework, also plays a large number of physiological roles in activating the immune system, aiding in colonization, evading antibiotics and hostresponses, as well as inter-species recognition (Clarke and Weiser, 2011; Royet et al., 2011; Mesnage et al., 2014). Using high-resolution imaging (cryo-electron tomography and atomic force microscopy) and computational modeling, studies have begun to explain how cell wall composition effects the biophysical properties of cells (Tocheva et al., 2013; de Pedro and Cava, 2015). Genetic and cell biology approaches have demonstrated the role of LD-transpeptidation in mediating lysozyme resistance and bacterial virulence (Schleifer and Kandler, 1972; Schoonmaker et al., 2014; Stankeviciute et al., 2019). Thus, HPLC is a powerful tool to connect PG composition and structure to its physiological impact.

\section{Materials and Reagents}

1. $50 \mathrm{ml}$ polypropylene conical tubes (Nunc, catalog number: 339653 )

2. Micro magnetic stir bar (Science ware, catalog number: F37121-0012)

3. $2.0 \mathrm{ml}$ Safe-lock microcentrifuge tubes (Eppendorf, catalog number: 022363352)

4. $1.7 \mathrm{ml}$ microcentrifuge tubes (VWR, catalog number: 87003-294)

5. MColorpHast $\mathrm{pH}$ test strips ( $\mathrm{pH} 0-6$ ) (Millipore Sigma, catalog number: 1095310001)

6. $1 \mathrm{ml}$ syringe (Becton Dickinson, catalog number: 309597 )

7. Millex-GV syringe filter unit, $0.22 \mu \mathrm{m}$ (Millipore Sigma, catalog number: SLGV033R)

8. $12 \times 32 \mathrm{~mm}$ screw neck HPLC vials (Waters, catalog number: 186000273)

9. Bottle top vacuum filter (VWR, catalog number: 10040-468)

10. Caulobacter crescentus strain NA1,000 (Laboratory strain, available upon request)

11. Bactopeptone (BD Biosciences, catalog number: 211677)

12. Yeast extract (BD Biosciences, catalog number: 212750)

13. Magnesium sulfate heptahydrate $\left(\mathrm{MgSO}_{4} \cdot 7 \mathrm{H}_{2} \mathrm{O}\right)$ (Fisher, catalog number: $\left.\mathrm{BP} 213\right)$

14. Calcium chloride dihydrate $\left(\mathrm{CaCl}_{2} \cdot 2 \mathrm{H}_{2} \mathrm{O}\right)$ (Fisher, catalog number: $\left.\mathrm{BP} 510\right)$

15. Ethylenediaminetetraacetic acid (EDTA) (Fisher, catalog number: BP118)

16. Zinc sulfate heptahydrate $\left(\mathrm{ZnSO}_{4} \cdot 7 \mathrm{H}_{2} \mathrm{O}\right)$ (Millipore Sigma, catalog number: Z0251)

17. Iron sulfate heptahydrate $\left(\mathrm{FeSO}_{4} \cdot 7 \mathrm{H}_{2} \mathrm{O}\right)$ (ACROS Organics, catalog number: 423730050$)$

18. Manganese sulfate hydrate $\left(\mathrm{MnSO}_{4} \cdot 7 \mathrm{H}_{2} \mathrm{O}\right.$ ) (Millipore Sigma, catalog number: $\mathrm{M} 7634$ )

19. Copper (II) sulfate pentahydrate $\left(\mathrm{CuSO}_{4} \cdot 5 \mathrm{H}_{2} \mathrm{O}\right)$ (Millipore Sigma, catalog number: 209918 )

20. Cobalt (II) nitrate hexahydrate $\left(\mathrm{Co}\left(\mathrm{NO}_{3}\right)_{2} \cdot 6 \mathrm{H}_{2} \mathrm{O}\right)$ (Millipore Sigma, catalog number: 239267$)$

21. Sodium tetraborate decahydrate $\left(\mathrm{Na}_{2} \mathrm{~B}_{4} \mathrm{O}_{7} \cdot 10 \mathrm{H}_{2} \mathrm{O}\right)$ (Millipore Sigma, catalog number: $\mathrm{B} 9876$ )

22. Sulfuric acid (Millipore Sigma, catalog number: 320501)

23. Nitrilotriacetic acid $\left(\mathrm{C}_{6} \mathrm{H}_{9} \mathrm{NO}_{6}\right)$ (Millipore Sigma, catalog number: N9877)

24. Ammonium heptamolybdate tetrahydrate $\left(\mathrm{NH}_{4} \mathrm{Mo}_{7} \mathrm{O}_{24}\right)$ (Millipore Sigma, catalog number: 09878) 
25. Sodium phosphate dibasic $\left(\mathrm{Na}_{2} \mathrm{HPO}_{4}\right)$ (Fisher, catalog number: BP331)

26. Potassium phosphate monobasic $\left(\mathrm{KH}_{2} \mathrm{PO}_{4}\right)$ (Fisher, catalog number: $\mathrm{P} 285$ )

27. Imidazole (Millipore Sigma, catalog number: 12399)

28. Glucose (Fisher, catalog number: D16500)

29. Sodium glutamate (Millipore Sigma, catalog number: 49621)

30. Ammonium chloride $\left(\mathrm{NH}_{4} \mathrm{Cl}\right)$ (Fisher, catalog number: A661)

31. Sodium dodecyl sulfate (SDS) (Millipore Sigma, catalog number: L3771)

32. Pronase E (VWR, catalog number: VE629)

33. Tris base (Fisher, catalog number: BP152)

34. Sodium chloride ( $\mathrm{NaCl}$ (Fisher, catalog number: BP358)

35. Mutanolysin from Streptomyces globisporus ATCC 21553 (Millipore Sigma, catalog number: M9901)

36. Phosphoric acid $\left(\mathrm{H}_{3} \mathrm{PO}_{4}\right)$ (Millipore Sigma, catalog number: 79607 )

37. Sodium hydroxide $(\mathrm{NaOH})$ (Fisher, catalog number: $\mathrm{S} 318)$

38. Boric acid $\left(\mathrm{H}_{3} \mathrm{BO}_{3}\right)$ (Millipore Sigma, catalog number: $\mathrm{B} 6768$ )

39. Sodium borohydride $\left(\mathrm{NaBH}_{4}\right)$ (Millipore Sigma, catalog number: 452882)

40. HPLC-grade methanol (Millipore Sigma, catalog number: 34860 )

41. Sodium azide $\left(\mathrm{NaN}_{3}\right)$ (Fisher, catalog number: BP9221)

42. Peptone-Yeast Extract (PYE) media (see Recipes)

43. Hutner-Imidazole-Glucose-Glutamate (HIGG) growth media (see Recipes)

44. Concentrated Hutner base (per $1 \mathrm{~L}$ ) (see Recipes)

45. 0.5 M Phosphate buffer, $\mathrm{pH} 7.0$ (see Recipes)

46. HIGG media (see Recipes)

47. Pronase E buffer (see Recipes)

48. $50 \mathrm{mM}$ phosphate buffer ( $\mathrm{pH}$ 4.9) (see Recipes)

49. $500 \mathrm{mM}$ borate buffer ( $\mathrm{pH}$ 9) (see Recipes)

50. HPLC Buffer A (see Recipes)

51. HPLC Buffer B (see Recipes)

\section{Equipment}

1. ELGA PURELAB Flex 3 water purification system (ELGA LabWater)

2. Magnetic hot plate-stirrer (Thermo Scientific, catalog number: SP195025)

3. Sorvall Lynx 6000 Centrifuge (Thermo Scientific)

4. $50 \mathrm{ml}$ conical tube centrifuge rotor (Thermo Scientific, catalog number: Fiberlite F14-14x50cy)

5. $\mathrm{pH}$ meter (Fisher, catalog number: 13-636-AB150)

6. Sorvall $W X 80+$ ultracentrifuge (Thermo Scientific, catalog number: 75000080 )

7. Swinging bucket rotor TH-641 (Thermo Scientific, catalog number: 54295)

8. $14 \times 89 \mathrm{~mm}$ thickwall polycarbonate tube for TH-641 rotor (Seton Scientific 2013) 
9. Fixed angle rotor T-1270 (Thermo Scientific, catalog number: 08259)

10. $16 \times 76 \mathrm{~mm}$ thickwall polycarbonate tube for T-1270 rotor (Seton Scientific 2004)

11. Digital dry bath (Fisher, catalog number: 88-871-001)

12. $6 \times 1.5 \mathrm{ml}$ block for dry bath (Fisher, catalog number: $88-871-103$ )

13. $6 \times 2.0 \mathrm{ml}$ block for dry bath (Fisher, catalog number: $88-871-104$ )

14. Microcentrifuge (Eppendorf, model: 5424)

15. Glass culture tubes $(13 \times 100 \mathrm{~mm})$ (Fisher, catalog number: 14-961-27)

16. Microspatula (Fisher, catalog number: S50823)

17. Vortexer (Fisher, catalog number: 02-215-414)

18. Agilent 1260 Infinity II HPLC system including:
a. Agilent 1260 Infinity II Quaternary pump
b. Agilent 1260 Infinity II Multisampler
c. Agilent 1260 Infinity II Multicolumn thermostat
d. Agilent 1260 Infinity II Diode array detector (DAD)
e. Agilent 1260 Infinity II Quaternary Pump
f. Agilent 1260 Infinity II Analytical-scale fraction collector

19. Hypersil ODS C18 HPLC column ( $3 \mu \mathrm{m}$ particles, $4.6 \mathrm{~mm}$ diameter, $250 \mathrm{~mm}$ length) (Thermo Scientific, catalog number: $30103-254630$ )

20. Uniguard guard cartridge holder (Thermo Scientific, catalog number: 850-00)

21. Hypersil ODS C18 guard cartridge ( $3 \mu \mathrm{m}$ particles, $4 \mathrm{~mm}$ diameter, $10 \mathrm{~mm}$ length) (Thermo Scientific, catalog number: 30103-014001)

22. Vacufuge concentrator (Eppendorf, model: 022820109)

\section{Software}

1. Matlab R2018b (Mathworks)

2. Chromanalysis v. 1.0 (Desmarais et al., 2015)

\section{Procedure}

This procedure is largely based on previously described protocols (Glauner, 1988; Desmarais et al., 2014). We include additional details for muropeptide separation by HPLC as well as methods for running consecutive samples with column cleaning and re-equilibration steps.

A. Inoculation and growth of bacterial cultures

1. Inoculate $2.5 \mathrm{ml}$ PYE media with a single colony of Caulobacter crescentus from an agar plate or directly from a freeze-down culture and grow overnight at $30^{\circ} \mathrm{C}$ with shaking at $200 \mathrm{rpm}$.

2. The next day, back-dilute the culture into $500 \mathrm{ml}$ of HIGG media (containing the desired phosphate concentration). Incubate this culture for $48 \mathrm{~h}$ at $30^{\circ} \mathrm{C}$ with $200 \mathrm{rpm}$ shaking. 
B. Muropeptide purification

\section{Day 1-Cell lysis}

1. Bring $700 \mathrm{ml}$ of water to a boil in a glass beaker on a stirrer-hot plate set to $450{ }^{\circ} \mathrm{C}$. For each culture to be processed, prepare a $50 \mathrm{ml}$ conical tube containing $6 \mathrm{ml}$ of $6 \%(\mathrm{w} / \mathrm{v})$ SDS and a micro stir bar, place the tube in the boiling water, and turn on the magnetic stirrer to $300 \mathrm{rpm}$ (Figure 1).

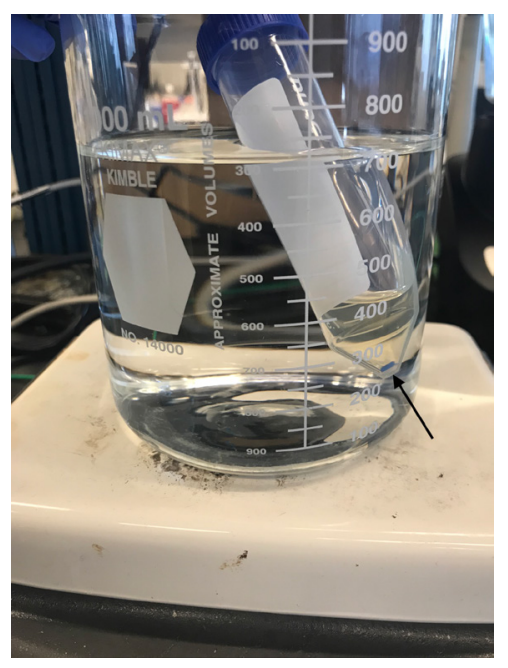

Figure 1. Cell lysis. Cells in 4\% SDS are boiled with stirring for $3 \mathrm{~h}$. The arrow indicates the micro stir bar.

2. Harvest the cells after $48 \mathrm{~h}$ by centrifugation at $12,000 \times g$ for $10 \min \left(4{ }^{\circ} \mathrm{C}\right)$. Decant the supernatant. The starved cells are very buoyant and some of the pellet will slip away.

3. Resuspend the pellet in $3 \mathrm{ml}$ of HIGG media and quickly transfer to the preheated $50 \mathrm{ml}$ conical tubes to yield a final concentration of $4 \%$ SDS (w/v).

4. Boil the samples for $3 \mathrm{~h}$ with continuous stirring, periodically adding water to the beaker when necessary. Do not remove from heat too early as this step is critical for complete cell lysis as well as the inactivation of cell wall altering enzymes. After $3 \mathrm{~h}$, turn off the heat and continue to stir the lysed cultures overnight.

\section{Day 2-Enzymatic digestions}

1. Check whether the SDS has precipitated overnight; if so, boil the sample for one hour to redissolve the SDS. Collect the sacculi by centrifugation at $276,000 \mathrm{xg}$ for $1 \mathrm{~h}$ in a TH-641 rotor. Spin at $20^{\circ} \mathrm{C}$ to avoid SDS precipitation. Resuspend the pellet in $6.5 \mathrm{ml}$ ultrapure water and centrifuge the sample at $329,738 \times \mathrm{g}$ for $30 \mathrm{~min}\left(20^{\circ} \mathrm{C}\right)$ in a T-1270 rotor.

2. Repeat this washing two times. If bubbles are still seen in the sample, add an extra wash to fully remove SDS (Figure 2). 


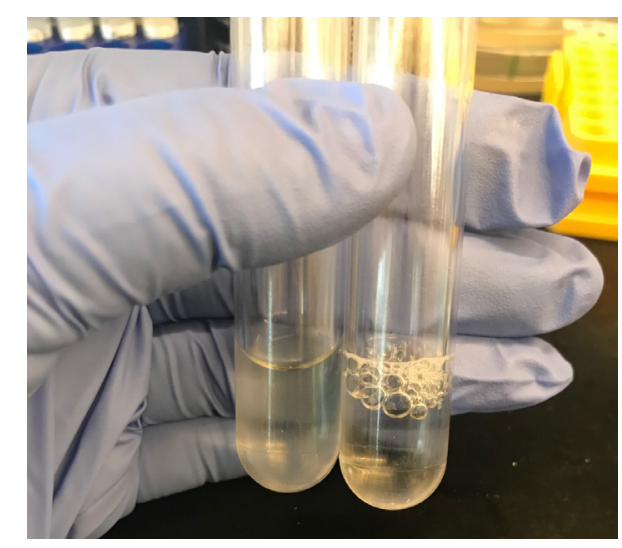

Figure 2. SDS removal. Samples washed in ultra-pure water should be transparent (left tube) and have lost the sudsy appearance with multiple washes (right tube).

3. Prepare $1 \mathrm{mg} / \mathrm{ml}$ Pronase $\mathrm{E}$ in $10 \mathrm{mM}$ Tris $-\mathrm{HCl}(\mathrm{pH} 7.2)+0.06 \% \mathrm{w} / \mathrm{v} \mathrm{NaCl}$. Activate the Pronase $\mathrm{E}$ by heating the stock solution at $60^{\circ} \mathrm{C}$ in a heat block for a minimum of 30 min (Figure 3 ).

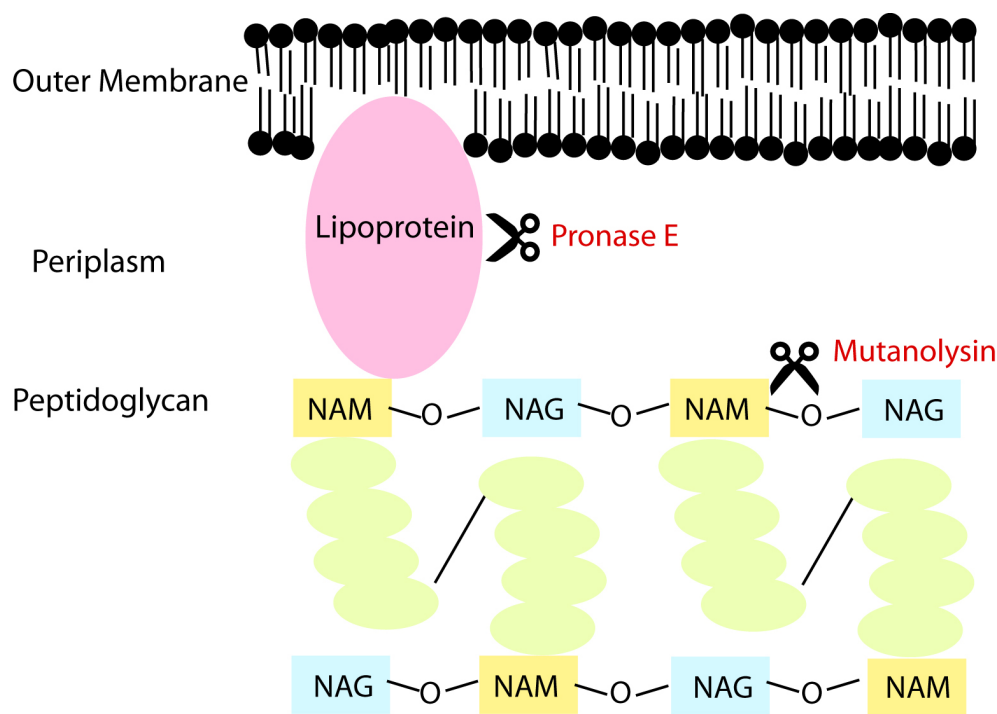

Figure 3. Enzymatic digestions. The cell envelope is digested with Pronase $E$ to eliminate lipoproteins linking the outer membrane to the peptidoglycan. The intact sacculus is digested into muropeptide fragments that cleave along the glycan backbone.

4. Resuspend each sample pellet in $900 \mu \mathrm{l}$ of $10 \mathrm{mM}$ Tris- $\mathrm{HCl}(\mathrm{pH} \mathrm{7.2)}+0.06 \% \mathrm{w} / \mathrm{v} \mathrm{NaCl}$ and transfer to a safe-lock microcentrifuge tube. Add $100 \mu \mathrm{l}$ of the activated Pronase $\mathrm{E}$ to the tube and incubate for a minimum of $2 \mathrm{~h}$ on a $60^{\circ} \mathrm{C}$ heat block. Pronase $\mathrm{E}$ is a protease that will digest lipoproteins associated with the peptidoglycan.

5. Add $200 \mu \mathrm{l}$ of $6 \%$ SDS (w/v) to the digested samples and boil them in a $100{ }^{\circ} \mathrm{C}$ dry bath for 30 min to stop the proteolysis. 
6. Resuspend the sacculi in $6.5 \mathrm{ml}$ ultrapure water and centrifuge them at 329,738 $\times \mathrm{g}$ for $30 \mathrm{~min}$ $\left(20^{\circ} \mathrm{C}\right.$ ) in a T-1270 rotor to wash out the SDS. Repeat the washing two times as before (or as long as necessary to eliminate any bubbles).

7. Prepare $1 \mathrm{mg} / \mathrm{ml}$ mutanolysin stocks in $50 \mathrm{mM}$ phosphate buffer $(\mathrm{pH} 4.9)$, aliquot $40-50 \mu \mathrm{l}$ into microcentrifuge tubes, and store the tubes at $-20^{\circ} \mathrm{C}$.

8. After the last wash, resuspend the peptidoglycan pellet in $75-200 \mu \mathrm{l}$ of $50 \mathrm{mM}$ sodium phosphate buffer ( $\mathrm{pH} \mathrm{4.9)}$ and transfer the sample to a $1.7 \mathrm{ml}$ microcentrifuge tube. This volume will depend on how much peptidoglycan material is in the sample. For example, sacculi from a $500 \mathrm{ml} C$. crescentus culture at $\mathrm{OD}_{660}$ of $0.8-1.0$ were resuspended in $200 \mu \mathrm{l}$. Add mutanolysin to the sample to a final concentration of $40 \mu \mathrm{g} / \mathrm{ml}$ and digest overnight in a $37^{\circ} \mathrm{C}$ dry bath (at least 10 h).

\section{Day 3-Sample preparation for HPLC}

1. Inactivate the muramidase by boiling the samples in a $100^{\circ} \mathrm{C}$ dry bath for $5 \mathrm{~min}$.

2. Remove undigested material by centrifugation at $16,000 \times g$ at room temperature for $10 \mathrm{~min}$. Carefully transfer the supernatant into a $13 \times 100 \mathrm{~mm}$ glass tube without disturbing the pellet.

3. Add $500 \mathrm{mM}$ Borate buffer $(\mathrm{pH} 9)$ to the supernatant to a final concentration of $100 \mathrm{mM}$.

4. Add approximately half a micro-spatula amount $(\sim 6 \mathrm{mg})$ of sodium borohydride into each sample (Figure 4). Vigorous bubbling should be seen immediately, after which small bubbles will continue to rise in the solution. Reduce the muropeptides at room temperature for a minimum of $30 \mathrm{~min}$. Vortex the tube gently to ensure complete mixing of the sodium borohydride. Caution: If too much sodium borohydride is added, it will precipitate during the $\mathrm{pH}$ titration and this will ruin the muropeptide purification.

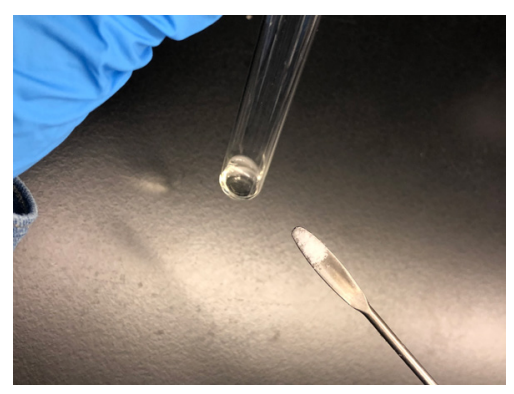

Figure 4. Reduction of muropeptides with sodium borohydride. Approximately $0.6 \mathrm{mg}$ of sodium borohydride (half a micro-spatula) is added to the sample for muropeptide reduction.

5. Acidify the reduced muropeptides to $\mathrm{pH} 3.0-4.0$ (the isoelectric point of the muropeptides is approximately 3.5). Start by adding $15 \mu \mathrm{l}$ of $50 \%$ phosphoric acid (vigorous bubbling will be seen) and gently vortex the tube to ensure thorough mixing. Test the $\mathrm{pH}$ by placing a $1 \mu \mathrm{l}$ drop of sample onto the $\mathrm{pH}$ indicator paper. Continue to add phosphoric acid in increments of $5 \mu \mathrm{l}$ until the $\mathrm{pH}$ is 5.5-6.0 (typically 1-2 additions). Continue adding phosphoric acid in increments of $1 \mu$ until reaching a pH between 3.0 and 4.0. 
6. Transfer the samples to a $1 \mathrm{ml}$ syringe and filter them through a Millex-GV syringe filter directly into a 12 x $32 \mathrm{~mm}$ HPLC vial. Samples can be stored long-term at $-20^{\circ} \mathrm{C}$.

C. HPLC set-up and sample analysis

1. While directing flow into the waste container, wash all 4 pump lines of the Agilent HPLC system with ultra-pure water for a minimum of $10 \mathrm{~min}$. Close the waste valve and wash the internal tubing by flushing with ultra-pure water for an additional $10 \mathrm{~min}$.

2. Connect pump A with Solvent A (Recipe 9), pump B with Solvent B (Recipe 9), pump C with HPLC-grade methanol and pump $D$ with ultra-pure water. While directing flow to the waste container, flush each line with its respective solvent.

3. Set the temperature of the column incubator to $55^{\circ} \mathrm{C}$. Close the waste valve and set the flowrate to $0.5 \mathrm{ml} / \mathrm{min}$ from Line $\mathrm{D}(100 \%$ Ultra-pure water).

4. Prepare the HPLC column by first attaching the Uniguard column containing a guard cartridge. Attach the column to the HPLC system by first allowing 5-6 drops of water to go into the upstream end of the column. Firmly tighten the upstream connector and wait for the water to drip from the downstream end before connecting the other end of the column.

5. Wash the column with ultrapure water for $20 \mathrm{~min}$ and ensure that the column pressure does not exceed 150 bar. Set the DAD detector to collect the absorbance at $205 \mathrm{~nm}$.

6. Equilibrate the column with Solvent $A$ at $0.5 \mathrm{ml} / \mathrm{min}$ for $50 \mathrm{~min}$. The column pressure and UV absorbance will stabilize during this step.

7. Prepare the HPLC samples as follows. Place a $100 \mu \mathrm{l}$ insert into a clean HPLC vial and add 50$90 \mu \mathrm{l}$ of sample to the insert. Prepare 2 vials with ultrapure water which will be used to blank the system as well as during cleanup. Arrange the vials in the autosampler unit.

8. If collecting peaks for further analysis by mass spectrometry, enable time-based fraction collection to collect the desired peaks. Place the appropriate number of collection tubes in the fraction collector according to the number of collected peaks. Each tube will collect approximately $100-450 \mu \mathrm{l}$ of sample depending on the duration of the fraction collection window (10-50 s). Since the elution time can vary slightly from run to run, we recommend collecting extra fractions before and after the expected elution time to ensure recovery of the desired peak.

9. The HPLC method consists of a $135 \mathrm{~min}$ linear gradient $(0.5 \mathrm{ml} / \mathrm{min})$ from $100 \%$ Solvent $A$ to $100 \%$ Solvent $B$. To re-equilibrate the column between samples, continue flowing $100 \%$ Solvent B $(0.5 \mathrm{ml} / \mathrm{min})$ for $5 \mathrm{~min}$, followed by a $25 \mathrm{~min}$ linear gradient to $100 \%$ Solvent $\mathrm{A}$, and finally an additional $25 \mathrm{~min}$ of $100 \%$ Solvent A. At the end of this washing protocol, the pressure and absorbance at $205 \mathrm{~nm}$ should be stabilized.

10. Prior to running muropeptide samples, inject $50 \mu \mathrm{l}$ of ultra-pure water into the HPLC system to serve as a blank for background subtraction. For the muropeptide samples, inject $40-80 \mu$; be certain not to inject more than the total volume of the sample to ensure that an air bubble is not introduced into the HPLC system. 
11. After the last sample has completed, wash the system and the column by injecting $20 \mu$ l of ultrapure water and running the following washing method. Begin with a 30 min flush with $100 \%$ water $(0.2 \mathrm{ml} / \mathrm{min})$, followed by a $10 \mathrm{~min}$ linear gradient to $100 \%$ methanol. Wash with $100 \%$ methanol for $60 \mathrm{~min}$ followed by a $10 \mathrm{~min}$ linear gradient to $10 \%$ methanol/90\% water. Flush the column with $10 \%$ methanol/ $90 \%$ water for an additional 10 min before removing the column for storage.

12. If fractions were collected, combine the fractions containing the peak of interest and remove the solvent using a vacufuge concentrator. Set the vent mode to 'aqueous' and spin the samples in the vacufuge concentrator until dry, typically $30-60$ min at $30^{\circ} \mathrm{C}$. A small translucent, white pellet may be seen on the bottom of the tube. These samples are suitable for LC/MS analysis.

13. The HPLC trace can be quantified using the Matlab-based Chromanalysis software as previously described (Desmarais et al., 2015).

\section{Data analysis}

The protocol above can be used to compare the muropeptide compositions of bacteria growing in different nutrient environments. For $C$. crescentus, phosphate starvation leads to an increase in LDtranspeptidation (Figure 5).

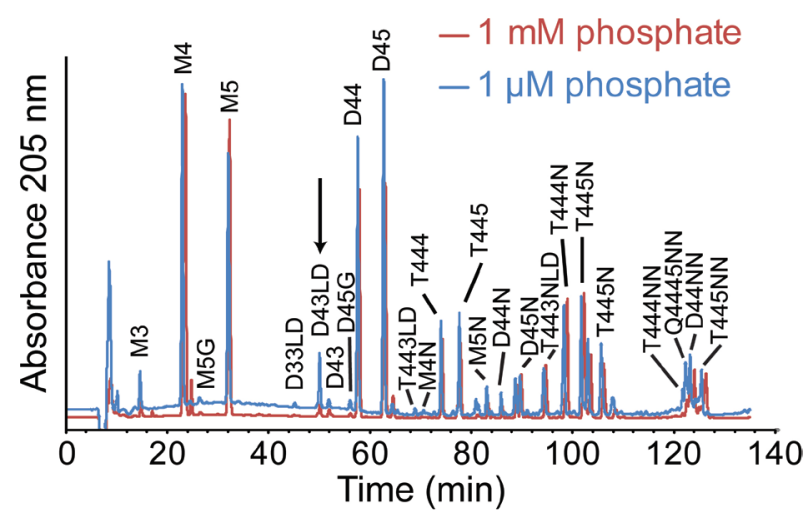

Figure 5. Muropeptide analysis of $\boldsymbol{C}$. crescentus grown in different phosphate concentrations. Muropeptides were purified from Caulobacter crescentus grown in HIGG media with $1 \mathrm{mM}$ or $1 \mu \mathrm{M}$ phosphate and analyzed via HPLC. The arrow indicates a peak uniquely present in the $1 \mu \mathrm{M}$ phosphate chromatogram. Major peaks were labeled based on previous analysis of $C$. crescentus muropeptides (Takacs et al., 2010). LD-crosslinks were labeled based on previous analysis of $E$. coli muropeptides (Glauner, 1988) and confirmed by LC/MS. This figure is reprinted with permission from John Wiley and Sons (Stankeviciute et al., 2019).

\section{Notes}

1. The protocol for operating the HPLC system may vary depending on your particular instrumentation. For an overview of HPLC operation, we recommend the article and 
accompanying video from the JoVE Science Education Database (https://www.jove.com/science-education/10156/high-performance-liquid-chromatographyhplc).

2. Prior to peak quantification, perform background subtraction using the blank-run (water sample).

\section{Recipes}

1. Peptone-Yeast Extract (PYE) media (1 L)

$2.0 \mathrm{~g}$ peptone

$1.0 \mathrm{~g}$ yeast extract

$1 \mathrm{mM} \mathrm{MgSO}_{4}$

$0.5 \mathrm{mM} \mathrm{CaCl}_{2}$

2. Hutner-Imidazole-Glucose-Glutamate (HIGG) media (Poindexter, 1978)

There are several stock solutions required for this media:

a. Metals "44" (per $100 \mathrm{ml}$ )

$1.3 \mathrm{ml} 0.5 \mathrm{M}$ disodium EDTA

$1,095.0 \mathrm{mg} \mathrm{ZnSO} \cdot \cdot 7 \mathrm{H}_{2} \mathrm{O}$

$500.0 \mathrm{mg} \mathrm{FeSO} \cdot 7 \cdot 7 \mathrm{H}_{2} \mathrm{O}$

$154.0 \mathrm{mg} \mathrm{MnSO} \cdot \mathrm{H}_{2} \mathrm{O}$

$39.2 \mathrm{mg} \mathrm{CuSO} \cdot 5 \mathrm{H}_{2} \mathrm{O}$

$24.8 \mathrm{mg} \mathrm{Co}\left(\mathrm{NO}_{3}\right)_{2} \cdot 6 \mathrm{H}_{2} \mathrm{O}$

$17.7 \mathrm{mg} \mathrm{Na} 2 \mathrm{~B}_{4} \mathrm{O}_{7} \cdot 10 \mathrm{H}_{2} \mathrm{O}$

Bring volume to $100 \mathrm{ml}$ with distilled water

Add 2-3 drops of sulfuric acid to prevent precipitation

b. Concentrated Hutner base (per $1 \mathrm{~L}$ )

$10.0 \mathrm{~g}$ Nitrilotriacetic acid

$29.59 \mathrm{~g} \mathrm{MgSO}_{4} \cdot 7 \mathrm{H}_{2} \mathrm{O}$

$3.335 \mathrm{~g} \mathrm{CaCl}_{2} \cdot 2 \mathrm{H}_{2} \mathrm{O}$

$9.25 \mathrm{mg}\left(\mathrm{NH}_{4}\right)_{6} \mathrm{Mo}_{7} \mathrm{O}_{24} \cdot 4 \mathrm{H}_{2} \mathrm{O}$

$99.0 \mathrm{mg} \mathrm{FeSO} \cdot 7 \mathrm{H}_{2} \mathrm{O}$

$50.0 \mathrm{ml}$ Metals " 44 "

Distilled water to $1,000 \mathrm{ml}$

i. Before adding all reagents, dissolve nitrilotriacetic acid and neutralize with $\mathrm{KOH}$; approximately $5.6 \mathrm{~g} \mathrm{KOH}$ will be required

ii. Add the rest of the components and adjust the $\mathrm{pH}$ to 6.6-6.8 before adjusting the volume

iii. Bring the solution to $1,000 \mathrm{ml}$ with distilled water

iv. Sterilize the solution by filtration (do not autoclave)

c. $0.5 \mathrm{M}$ Phosphate buffer, $\mathrm{pH} 7.0$

Mix $61 \mathrm{ml}$ of $0.5 \mathrm{M} \mathrm{Na}_{2} \mathrm{HPO}_{4}$ with $39 \mathrm{ml}$ of $0.5 \mathrm{M} \mathrm{KH}_{2} \mathrm{PO}_{4}$ and sterilize by autoclaving 

d. $1 \mathrm{M}$ imidazole, $\mathrm{pH} 7.0$ (autoclaved)
e. $20 \%(w / v)$ glucose (sterile filtered)
f. $20 \%(w / v)$ sodium glutamate (sterile filtered)
g. $50 \mathrm{mM} \mathrm{CaCl} 2$ (autoclaved)
h. $1 \mathrm{M} \mathrm{NH}_{4} \mathrm{Cl}$ (autoclaved)

To prepare the HIGG media, autoclave the desired amount of distilled water and add the following components to the final concentrations listed:

$5 \mathrm{mM}$ imidazole, $\mathrm{pH} 7.0$

$2 \%(\mathrm{v} / \mathrm{v})$ Hutner's base

$1 \mathrm{mM} \mathrm{CaCl}_{2}$

$0.15 \%(w / v)$ glucose

$0.15 \%(\mathrm{w} / \mathrm{v})$ sodium glutamate

$8.9 \mathrm{mM} \mathrm{NH}_{4} \mathrm{Cl}$

$1 \mu \mathrm{M}-1,000 \mu \mathrm{M}$ phosphate

3. Pronase $\mathrm{E}$ buffer

$10 \mathrm{mM}$ Tris, $\mathrm{pH} 7.2$

$0.06 \%(w / v) \mathrm{NaCl}$

4. $50 \mathrm{mM}$ phosphate buffer, $\mathrm{pH} 4.9(100 \mathrm{ml})$
a. Dissolve $0.2 \mathrm{~g} \mathrm{NaOH}$ in $\sim 90 \mathrm{ml}$ water
b. Adjust the $\mathrm{pH}$ of the solution to 4.9 with phosphoric acid
c. Bring the total volume to $100 \mathrm{ml}$ with water

5. $500 \mathrm{mM}$ borate buffer, $\mathrm{pH} 9(500 \mathrm{ml})$
a. Dissolve $15.46 \mathrm{~g}$ boric acid in $\sim 480 \mathrm{ml}$ water
b. Adjust the $\mathrm{pH}$ to 9.0 with $\mathrm{NaOH}$
c. Bring the total volume to $500 \mathrm{ml}$ with water

6. HPLC buffers

Buffer A: $50 \mathrm{mM} \mathrm{NaPO}_{4} \mathrm{pH} 4.35,0.4 \% \mathrm{NaN}_{3}$
a. Dissolve $2.0 \mathrm{~g} \mathrm{NaOH}$ into $\sim 950 \mathrm{ml}$ ultrapure water
b. Adjust the $\mathrm{pH}$ to 4.35 with phosphoric acid
c. Add $200 \mu \mathrm{l} 2 \%(\mathrm{w} / \mathrm{v}) \mathrm{NaN}_{3}$
d. Bring the total volume to $1,000 \mathrm{ml}$ with ultrapure water
e. Re-adjust the $\mathrm{pH}$ to 4.35
f. Sterile filter before use

Buffer B: $75 \mathrm{mM} \mathrm{NaPO}_{4} \mathrm{pH} 4.95,15 \%$ methanol
a. Dissolve $3.0 \mathrm{~g} \mathrm{NaOH}$ into $\sim 800 \mathrm{ml}$ ultrapure water
b. Adjust the $\mathrm{pH}$ to 4.95 with phosphoric acid
C. Bring the total volume to $850 \mathrm{ml}$ with ultrapure water
d. Add $150 \mathrm{ml} \mathrm{HPLC-grade} \mathrm{methanol}$ 
e. Re-adjust the $\mathrm{pH}$ to 4.95

f. Sterile filter before use

\section{Acknowledgments}

We thank Amanda Miguel and K.C. Huang (Stanford University) for their guidance in muropeptide purification. We have generally adapted their protocol for UPLC-based separation (Desmarais et al., 2014) for use on an HPLC system. This work was supported by a grant from the National Science Foundation (MCB-1553004) to E.A.K.

\section{Competing interests}

The authors have no competing interests to declare.

\section{References}

1. Clarke, T. B. and Weiser, J. N. (2011). Intracellular sensors of extracellular bacteria. Immunol Rev 243(1): 9-25.

2. de Pedro, M. A. and Cava, F. (2015). Structural constraints and dynamics of bacterial cell wall architecture. Front Microbiol 6: 449.

3. Desmarais, S. M., Cava, F., de Pedro, M. A. and Huang, K. C. (2014). Isolation and preparation of bacterial cell walls for compositional analysis by ultra performance liquid chromatography. $J$ Vis Exp 83: e51183.

4. Desmarais, S. M., Tropini, C., Miguel, A., Cava, F., Monds, R. D., de Pedro, M. A. and Huang, K. C. (2015). High-throughput, highly sensitive analyses of bacterial morphogenesis using ultra performance liquid chromatography. J Biol Chem 290(52): 31090-100.

5. Glauner, B. (1988). Separation and quantification of muropeptides with high-performance liquid chromatography. Anal Biochem 172(2): 451-64.

6. Levefaudes, M., Patin, D., de Sousa-d'Auria, C., Chami, M., Blanot, D., Herve, M., Arthur, M., Houssin, C. and Mengin-Lecreulx, D. (2015). Diaminopimelic acid amidation in Corynebacteriales: new insights into the role of LtsA in peptidoglycan modification. $J$ Biol Chem 290(21): 13079-94.

7. Mesnage, S., Dellarole, M., Baxter, N. J., Rouget, J. B., Dimitrov, J. D., Wang, N., Fujimoto, Y., Hounslow, A. M., Lacroix-Desmazes, S., Fukase, K., Foster, S. J. and Williamson, M. P. (2014). Molecular basis for bacterial peptidoglycan recognition by LysM domains. Nat Commun 5: 4269.

8. Poindexter, J. S. (1978). Selection for nonbuoyant morphological mutants of Caulobacter crescentus. J Bacteriol 135(3): 1141-5.

9. Royet, J., Gupta, D. and Dziarski, R. (2011). Peptidoglycan recognition proteins: modulators of the microbiome and inflammation. Nat Rev Immunol 11(12): 837-51. 
10. Schleifer, K. H. and Kandler, O. (1972). Peptidoglycan types of bacterial cell walls and their taxonomic implications. Bacteriol Rev 36(4): 407-77.

11. Schoonmaker, M. K., Bishai, W. R. and Lamichhane, G. (2014). Nonclassical transpeptidases of Mycobacterium tuberculosis alter cell size, morphology, the cytosolic matrix, protein localization, virulence, and resistance to beta-lactams. J Bacteriol 196(7): 1394-402.

12. Stankeviciute, G., Miguel, A. V., Radkov, A., Chou, S., Huang, K. C. and Klein, E. A. (2019). Differential modes of crosslinking establish spatially distinct regions of peptidoglycan in Caulobacter crescentus. Mol Microbiol 111(4): 995-1008.

13. Takacs, C. N., Poggio, S., Charbon, G., Pucheault, M., Vollmer, W. and Jacobs-Wagner, C. (2010). MreB drives de novo rod morphogenesis in Caulobacter crescentus via remodeling of the cell wall. $J$ Bacteriol 192(6): 1671-84.

14. Tocheva, E. I., Lopez-Garrido, J., Hughes, H. V., Fredlund, J., Kuru, E., Vannieuwenhze, M. S., Brun, Y. V., Pogliano, K. and Jensen, G. J. (2013). Peptidoglycan transformations during Bacillus subtilis sporulation. Mol Microbiol 88(4): 673-86.

15. Vollmer, W. (2008). Structural variation in the glycan strands of bacterial peptidoglycan. FEMS Microbiol Rev 32(2): 287-306. 